\title{
Randomized Controlled Trial Comparing the Efficacy and Safety of Epidural Infiltration of Particulate Versus Nonparticulate Steroids in the Treatment of Patients with Sciatic Pain
}

\author{
Nazia Nazir ${ }^{1}$, Savita Gupta ${ }^{* 1}$, Vikas Saxena ${ }^{2}$ \\ ${ }^{1}$ Department of Anaesthesia, Government Institute of Medical Sciences, Greater Noida, UP 201310, India \\ ${ }^{2}$ Department of Orthopaedics, Government Institute of Medical Sciences, Greater Noida, UP 201310, India \\ *Corresponding author: Savita Gupta; (https://orcid.org/0000-0002-3104-7368); dr.gsavita@ gmail.com
}

Received 06 December 2021;

Accepted 22 December 2021;

Published 24 December 2021

\begin{abstract}
Introduction: Epidural corticosteroid injections are widely used to treat low back pain, but doubts exist about the relative efficacy of particulate versus non-particulate corticosteroids. Epidural corticosteroid injections were performed in 75 patients with chronic radicular pain were evaluated for epidural corticosteroid injections to determine if there was a difference in the efficacy of triamcilone acetate, methylprednisolone acetate, and dexamethasone. Methods: 75 patients presenting with debilitating radicular pain were randomized to receive an injection of triamcilone acetate $40 \mathrm{mg} / \mathrm{ml}$, methylprednisolone acetate $40 \mathrm{mg} / \mathrm{ml}$, and dexamethasone phosphate $7.5 \mathrm{mg} / \mathrm{ml}$ at equal doses. Data were collected at 1-month and 3-month follow-up. The primary outcome of the present study was reduction in pain on a visual analog scale (VAS) at 3 months, while the secondary outcome was the type and number of complications in the study group. Results: Regardless of baseline score VAS, pain score decreased in all patients at one and three months. The patients with VAS of very severe also showed a statistically significant success rate at one and three month follow-up $[\mathrm{p}=0.043]$. No serious complications occurred in all three groups. Conclusion: According to this study, pain relief and functional improvement are similar among all three methylprednisolone acetate, triamcilone acetate and dexamethasone phosphate at 3 months.
\end{abstract}

Keywords: epidural corticosteroid, non-particulate steroids, particulate steroids, sciatica, visual analogue scale

\section{Introduction}

Low back pain and sciatica is a significant health problem that significantly affects quality of life. The lifetime prevalence of low back pain is reported to be $50-80 \%{ }^{[1]}$. All patients with disk herniation are usually treated conservatively with a combination of weight loss, exercise, and physical therapy. Only in cases of extensive, excessive symptoms is surgery indicated. Epidural steroid injection may be used to treat pain in patients who do not respond to conservative measures ${ }^{[2]}$. Radicular pain may be related to inflammatory cytokines released by a herniated disk. Steroids reduce inflammation around the affected nerve, suppress ectopic discharges, and improve blood flow to the ischemic nerve root, resulting in pain relief ${ }^{[3]}$.

Epidural steroid preparations are divided into two classes: particulate preparations such as methylprednisolone, betamethasone, and triamcinolone, and nonparticulate preparations such as betamethasone sodium phosphate and dexamethasone phosphate. Particulate steroids such as methylprednisolone have a longer duration of action due to a local depot effect, which ensures a continuous release of the drug at the injection site over a long period of time ${ }^{[4]}$. However, non-particulate steroids are watersoluble steroids with small particle size and limited aggregation with rapid clearance and short duration of action ${ }^{[5]}$. Several clinical reports have reported possible complications such as paraplegia due to spinal cord ischemia during the procedure with particulate steroids ${ }^{[6,7]}$.

The efficacy of different types of steroid injections has shown varying effects in different clinical trials, with no clear conclusion ${ }^{[8,9]}$. The aim of this study was to compare the efficacy of particulate and non-particulate steroids in patients receiving epidural injections for radicular pain. The primary outcome of the present study was to compare the treatment-related mean change in VAS between particulate steroids and no particulate steroids. 


\section{Materials and Methods}

After approval by the institutional ethics committee, 75 patients were selected who suffered from chronic unilateral or bilateral sciatica and had not responded properly to conservative pain relief techniques.

All these patients had imaging with magnetic resonance imaging confirming the analysis of lower lumbar disc disease. The inclusion criteria for the selected patients were as follows: $\geq 18$ years of age, lumbar radicular symptoms below the knee consistent with lumbar magnetic resonance imaging pathology, pain for at least 6 months and no contraindication to intraaxial treatment. Patients with known neuropathy or use of steroids were excluded. These patients were randomly assigned to three groups: Group A, $\mathrm{B}$, and $\mathrm{C}$ received equivalent doses of methylprednisolone acetate $40 \mathrm{mg}$ (Depo-Medrol), triamcilone acetate $40 \mathrm{mg}$ (Kenacort), and dexamethasone phosphate (Dexasone) $7.5 \mathrm{mg}$ injected via spinal needle mixed with preservative-free saline and $4 \mathrm{ml}$ of $2 \%$ preservative-free xylocaine to obtain a volume of $20 \mathrm{ml}$. For the procedure, the patient was placed on the operating table in lateral position. After sterile preparation with betadine and spirit, the area was draped, the sacral hiatus was identified, and the skin was anaesthetized with $1 \%$ lidocaine. A $22 \mathrm{G}$ spinal needle (BD intima) was placed at a 45 degree with the needle bevel positioned ventrally then advanced through the sacrococcygeal ligament followed by a negative aspiration test and then confirmation by a 'Hoosh' test after which the drug was injected. Concealment (sealed opaque envelope) was performed by an investigator who prepared the drug solution under study. Pain scores before the procedure were obtained by the pain clinic nurses not involved in the study before the procedure using the VAS. At follow-up for the second epidural in 1-2 months, the VAS scores were again collected by the preoperative nursing staff. Patients were allowed to take acetaminophen for emergency analgesia for the first 4 weeks after the procedure. Patients were assessed at baseline and 1 month and 3 months after initiation of treatment. Subjective pain intensity was rated at VAS on a scale of 0 (no pain) to 10 (worst possible pain). Only those patients who had VAS $=0-2$ after therapy were considered a success. $\mathrm{P}<0.05$ was considered statistically significant. All statistical tests were performed using Statistical Package for the Social Sciences software (version 21.0; IBM, NY, USA).

\section{Results}

In the present study, the mean age of the patients in the three groups was examined. The mean age of patients in group A was 53.08 years with a standard deviation of 6.462 , in group B was 55.42 years with a standard deviation of 5.332 , and in group $C$ was 54.54 years with a standard deviation of 5.546, which were not significant $(\mathrm{p}=0.395)$. Most of the three groups were men $(\mathrm{p}=$ 0.258). Three patients dropped out after three months. In the present study the majority of the population were found to be in the age group of $56-60$ years which constituted $38.7 \%$, in the age group of 51-55 years it was $28 \%$ and in the age group of $46-50$ years it was $20 \%$ and $13.3 \%$ in the age group of $<45$ years. Preprocedure VAS and Postprocedure VAS between three steroid groups ( $\mathrm{p}=0.863$ and 0.738 respectively) was non-significant. [Table1]

Table 1: Demographics and dropout patients among the three groups

\begin{tabular}{|l|l|l|l|l|}
\hline Factor & Group A & Group B & Group C & P value \\
\hline Age, mean \pm SD(years) & $53.08 \pm 6.462$ & $55.42 \pm 5.332$ & $54.54 \pm 5.546$ & 0.395 \\
\hline Sex, male(\%) & $16(64)$ & $15(60)$ & $18(72)$ & 0.258 \\
\hline Pre VAS, mean \pm SD & $76.3 \pm 16.8$ & $78.3 \pm 17.6$ & $76.6 \pm 18.9$ & 0.863 \\
\hline Post VAS, mean \pm SD & $55.4 \pm 24.5$ & $59.8 \pm 21.6$ & $57.5 \pm 20.4$ & 0.738 \\
\hline Dropout patients at 1 month & 1 & 1 & 0 & \\
\hline Dropout patients at 3 month & 1 & 1 & 1 & \\
\hline
\end{tabular}

Maximum decrease in pain among patients was in Group A and B (86.9\%) but it was non-significant in comparison to Group C. More than $64.3 \%$ patients from the all groups responded well to the first injection itself. No complications were reported by patients including new neurological symptoms or new areas of pain. [Table 2]

Table 2: The comparison of outcome at 1 and 3 months against the age of the patients

\begin{tabular}{|l|l|l|l|l|}
\hline Groups & $\mathbf{1}$ months & 3 months & Failure \\
\cline { 2 - 5 } & Success & Failure & Success & $3(13 \%)$ \\
\hline Group A $(\mathbf{n = 2 3})$ & $16(69.5 \%)$ & $7(30 \%)$ & $20(86.9 \%)$ & $3(13 \%)$ \\
\hline Group B $(\mathbf{n = 2 3})$ & $15(65 \%)$ & $8(34 \%)$ & $20(86.9 \%)$ & $4(16.7 \%)$ \\
\hline Group C $(\mathbf{n}=\mathbf{2 4})$ & $14(58.3 \%)$ & $10(41.6 \%)$ & $20(83.3 \%)$ & \\
\hline
\end{tabular}

No patient presented with mild or moderate pain before the caudal epidural injection according to VAS scale. [Table 3]

Table 3: Complications in patients during procedure among the three groups

\begin{tabular}{|l|l|l|l|}
\hline Complication & Group A & Group B & Group C \\
\hline Attempts required for steroid placement & & & \\
One & 24 & 22 & 25 \\
Two & 1 & 3 & 0 \\
\hline Approach difficulty & 3 & 3 & 2 \\
\hline Increased local pain & 2 & 1 & 1 \\
\hline Increased lumbar pain & 1 & 2 & 1 \\
\hline Increased radicular pain & 0 & 0 & 1 \\
\hline Dural puncture & 0 & 0 & 0 \\
\hline
\end{tabular}




\begin{tabular}{|l|l|l|l|}
\hline Vasovagal reaction & 0 & 1 & 0 \\
\hline High blood pressure & 1 & 0 & 0 \\
\hline Hypotension (recorded during procedure) & 0 & 2 & 1 \\
\hline
\end{tabular}

In the present study, 5 patients did not return and were excluded from the analysis of the final outcome. Success and failure in the different groups are shown in Table 2. After a follow up period of 3 months, two patients had an increase in pain level (severe and very severe pain). The patients with VAS -very severe pain also showed a statistically significant success rate at one and three month follow up $[\mathrm{p}=0.043$ ] [Figure 1].

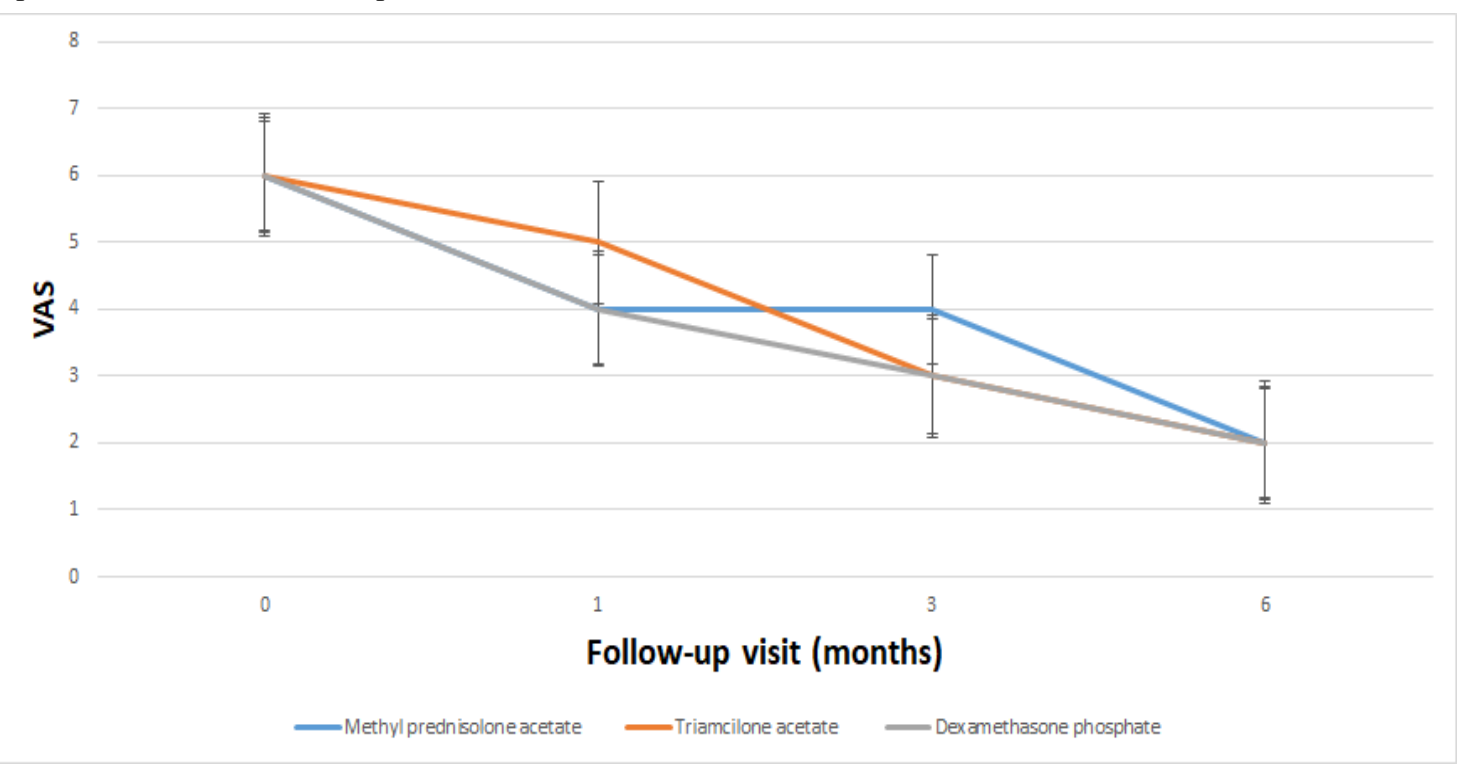

Figure 1: Evolution of VAS in the Methyl prednisolone acetate, Triamcilone acetate and Dexamethasone phosphate groups

\section{Discussion}

Chronic low back pain and its treatment are associated with high morbidity ${ }^{[10]}$. Although there is no clear aetiology for chronic low back pain, disc degeneration, disc herniation or inflammatory response could be responsible for low back pain ${ }^{[11,12]}$. $64.3 \%$ of patients from all groups responded well to the first injection.

Even though many studies showed a trend in favour of particulate steroids, none of the studies demonstrated statistical significance. A study by Park at el. ${ }^{[13]}$ showed VAS scores with triamcinolone compared to dexamethasone statistically significant. We examined the maximum change in VAS regardless of time period as the primary endpoint because our goal was to analyse the best possible pain relief reported with both particulate and nonparticulate steroid use. In the present study, it was observed that pain intensity decreased in all studied groups of VAS (moderate, severe and very severe) after caudal epidural corticosteroid administration. Response to therapy was comparable between these groups at both follow-ups studied ( $p>0.05$ ). Furthermore, patients with very severe pain achieved a success rate of $64.3 \%$ and $85.7 \%$ at one- and three-month follow-up, respectively, demonstrating that caudal epidural corticosteroid injection can be effective in patients with very severe pain. Techniques of injections and dosage of the steroid used suffer significant variations from centre to centre. One study showed minor variations in practice are likely to have no significant effect on an outcome ${ }^{[14]}$.

The present study also has several limitations. No image intensifier contrast epidurogram was used to accurately place the needle when performing the caudal epidural injection.

Caudal epidural steroid injection gives an easy, rapid, and easily performed day-care method that can offer significant pain relief. It may be considered as an alternative to operative management for patients who are at high risk of surgery or not responding well to any conservative treatment or on refusal to surgical intervention. Patients were discharged following injection so long periods of hospitalization and bed rest was avoided. No clinical evidence of dural puncture, bleeding, need for surgery or neurotoxicity were noted in this study.

\section{Conclusions}

In conclusion, we have observed that epidural corticosteroid injection may be useful in the treatment of patients with lumbosciatic pain. According to present study, pain relief and functional improvement at three months are similar for all the three steroids i.e. triamcilone acetate, methylprednisolone acetate and dexamethasone phosphate.

\section{Ethics approval and consent to participate}

The study was approved by the Institutional Ethics Committee (GIMS/IEC/HR/2019/09). A written informed consent was obtained from each participant.

\section{List of abbreviations}

VAS: visual analog scale

\section{Data Availability}

All the data used in writing the article are included in the manuscript

\section{Conflicts of Interest}

The authors declare that there is no conflict of interest regarding the publication of this article 


\section{Funding Statement}

This research work did not receive any specific grant from any funding agencies

\section{Authors' contributions}

NN, SG and VS made substantial contributions to conception and design of the study. Data collection done by SG. NN, SG and VS executed the experiment. All authors participated in drafting the article and approved the content for publication

\section{References}

[1] Fatoye, F, Gebrye, T, Odeyemi, I. Real-world incidence and prevalence of low back pain using routinely collected data. Rheumatol Int 2019;39, 619-26.

[2] Stanczak J, Blankenbaker DG, De Smet AA, Fine J. Efficacy of epidural injections of Kenalog and Celestone in the treatment of lower back pain. AJR Am J Roentgenol. 2003;181(5):1255-8.

[3] Blankenbaker DG, De Smet AA, Stanczak JD, Fine JP. Lumbar radiculopathy: treatment with selective lumbar nerve blocks--comparison of effectiveness of triamcinolone and betamethasone injectable suspensions. Radiology. 2005;237(2):738-41.

[4] Bensler S, Sutter R, Pfirrmann CWA, Peterson CK. Is there a difference in treatment outcomes between epidural injections with particulate versus non-particulate steroids? Eur Radiol. 2017;27(4):1505-1511.

[5] Iversen T, Solberg TK, Romner B, Wilsgaard T, Twisk J, Anke A, et al. Effect of caudal epidural steroid or saline injection in chronic lumbar radiculopathy: multicentre, blinded, randomised controlled trial. BMJ. 2011 Sep 13;343:d5278.

[6] Tagowski M, Lewandowski Z, Hodler J, Spiegel T, Goerres GW. Pain reduction after lumbar epidural injections using particulate versus non-particulate steroids: intensity of the baseline pain matters. Eur Radiol. 2019;29(7):3379-89.

[7] Bensler S, Sutter R, Pfirrmann CWA, Peterson CK. Particulate versus non-particulate corticosteroids for transforaminal nerve root blocks: Comparison of outcomes in 494 patients with lumbar radiculopathy. Eur Radiol. 2018;28(3):946-52.

[8] Tiso RL, Cutler T, Catania JA, Whalen K. Adverse central nervous system sequelae after selective transforaminal block: The role of corticosteroids. Spine J 2004; 4:468-74.
[9] Benzon HT, Chew TL, McCarthy RJ, Benzon HA, Walega DR. Comparison of the particle sizes of different steroids and the effect of dilution: a review of the relative neurotoxicities of the steroids. Anesthesiology. 2007 Feb;106(2):331-8.

[10] Kim D, Brown J. Efficacy and safety of lumbar epidural dexamethasone versus methylprednisolone in the treatment of lumbar radiculopathy: a comparison of soluble versus particulate steroids. Clin J Pain. 2011 JulAug;27(6):518-22.

[11] Schneider B, Varghis N, Kennedy DJ. Ideal Corticosteroid Choice for Epidural Steroid Injections: A Review of Safety and Efficacy. Curr Phys Med Rehabil Rep 2015; 3, 151-8.

[12] Dreyfuss P, Baker R, Bogduk N. Comparative effectiveness of cervical transforaminal injections with particulate and nonparticulate corticosteroid preparations for cervical radicular pain. Pain Med 2006;7(3):237-42.

[13] Park CH, Lee SH, Kim BI. Comparison of the effectiveness of lumbar transforaminal epidural injection with particulate and nonparticulate corticosteroids in lumbar radiating pain. Pain Med 2010;11:1654-8.

[14] Valat JP, Giraudeau B, Rozenberg S, Goupille P, Bourgeois P, Micheau-Beaugendre V, et al. Epidural corticosteroid injections for sciatica: a randomised, double blind, controlled clinical trial. Ann Rheum Dis. 2003 Jul;62(7):639-43.

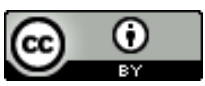

Open Access This article is licensed under a Creative Commons Attribution 4.0 International License, which permits use, sharing, adaptation, distribution and reproduction in any medium or format, as long as you give appropriate credit to the original author(s) and the source, provide a link to the Creative Commons license, and indicate if changes were made. The images or other third party material in this article are included in the article's Creative Commons license, unless indicated otherwise in a credit line to the material. If material is not included in the article's Creative Commons license and your intended use is not permitted by statutory regulation or exceeds the permitted use, you will need to obtain permission directly from the copyright holder. To view a copy of this license, visit https://creativecommons.org/licenses/by/4.0/.

(C) The Author(s) 2021 